\title{
The Study of Yu Xin's Integration into the Regime of the Northern Zhou Dynasty
}

\author{
Xiancheng He \\ Research Institute of Sichuan Old Revolution Area Development, Sichuan University of Arts and Science, Dazhou, China \\ Email: xlightwhite@163.com
}

How to cite this paper: He, X.C. (2019) The Study of Yu Xin's Integration into the Regime of the Northern Zhou Dynasty. Open Access Library Journal, 6: e5413. https://doi.org/10.4236/oalib.1105413

Received: April 19, 2019

Accepted: May 5, 2019

Published: May 8, 2019

Copyright $\odot 2019$ by author(s) and Open Access Library Inc.

This work is licensed under the Creative Commons Attribution International License (CC BY 4.0).

http://creativecommons.org/licenses/by/4.0/

\section{(c) (i) Open Access}

\begin{abstract}
From the first year of Baoding, Yu Xin's uncooperative attitude towards the regime of the Northern Zhou Dynasty gradually turned into his identification with the culture of it. After that, he opened his heart and tried to integrate into the Northern Zhou regime successfully. His specific performance is in six aspects: actively engaging in politics, writing the temple poems for the Northern Zhou Dynasty, eulogizing the regime of the Northern Zhou Dynasty with poems, writing inscriptions and epitaph for the meritorious statesmen of the Northern Zhou Dynasty, being concerned about the extinction of the Northern Qi Dynasty by Northern Zhou Dynasty, and being worried about the political situation in the late Northern Zhou Dynasty.
\end{abstract}

\section{Subject Areas}

History

\section{Keywords}

Yu Xin, The Northern Zhou Dynasty, Acculturation, Regime

\section{Introduction}

In the third year of Chengsheng, which is under the reign of Emperor Yuan of Liang of the Southern Dynasty (554), Yu Xin was ordered as an envoy to visit the Western Wei Dynasty and then was persuaded to stay there from for twenty-eight years by Yuwen Ta. At the beginning of entering the north (554-561), confronted with the sinister political environment, barren and plain literature environment, cold and dry natural environment and totally different eating habits, etc., Yu Xin bore disloyalty and showed an uncooperative attitude towards the regime of the Western Wei and the Northern Zhou Dynasty. Later, due to the change of the political situation of the Northern Zhou Dynasty and Yu Xin's 
mood, Yu Xin gradually recognized the culture of the Northern Zhou Dynasty and tried to integrate into the regime of the Northern Zhou Dynasty. In this process, what attempts did Yu Xin make? This will be the focus of this essay.

\section{Actively Engaging in Politics}

In the third year of Baoding (563 AD), Yu Xin was appointed as the sheriff of Hongnong county. Although he held this position for a short time, he showed great enthusiasm during his tenure and made good achievements, which helped him won the support of the people in Hongnong county [1]. In the fourth year of Jiande (575), he served as Sixianzhongdafu (an official position, somewhat like the highest supervision), and expressed his joy about taking the post in a poem named Taking office to Sixian office during The Spring Festival. "Mei Cheng was appointed in the illness. Gong Yu and Wang Ji became officials and assisted the Emperor together." [1] Teng Wangyou praised Yu Xin for his achievements in the post. "Competent in handling legal documents and competent in obtaining talents for the criminal department, Yu reached the highest level when he was appointed as Sixianzhongdafu." [1] In the following year, he served as the feudal provincial of Luo state, and wrote many poems in his office, expressing his concern for the regime of the Northern Zhou Dynasty. Also, he made great achievements in his official career in Lou state, for which Yuwen You praised "Officials dare not bribe and people dare not bully." "Just like Gou Ji governing Bing county and Liu Hong guarding Xiangyang.” [1]

\section{Eulogizing the Regime of the Northern Zhou Dynasty with Poems}

In the second year of Wucheng (560), Yuwen Yong succeeded to the throne as Emperor Wu. In October of the second year of Baoding (562), Emperor Wu of the Northern Zhou Dynasty preached martial arts in Shao Ling plateau. Yu Xin was happened in Chang'an and he wrote a poem named Follow the Emperor to Watch and Preach Martial Arts, to praise the martial arts achievements of Emperor Wu. His poem extremely described the magnificence of the scene, "Carrying out military exercises in Changyang, soldiers went into the obstacle around the barracks and the martial drilling fields. The army phalanx was like a cloud and divided into two lines, shaping like two wings of a wild goose... The sword of Longyuan can touch the Buffaloes Star, and the weak bow and arrows can make the enemy afraid... Drums beat and cavalry billows smoke. From time to time, the frightened monkey fell from the tree and flew about in all directions..." Most researchers believe $\mathrm{Yu}$ was forced to compose the poem but his view is not appropriate. Through the management of Yuwen Tai, Emperor Xiaomin and Emperor Ming in the Northern Zhou Dynasty, as well as Emperor Wu's efforts in the early years of the Northern Zhou Dynasty, the military force of the Northern Zhou Dynasty could reach the situation described by Yu Xin in his poem. Yu's praise of the emperor is true, not false adulation. Yu Xin also wrote two poems 
in the fifth year of Baoding (565) and the second year of Tianhe (567) respectively, Accompanying Royal Highness Prince Xu to the Army and Sending Emperor Wei to Conquer the North, describing the military pomp of the Northern Zhou Dynasty, “The singer's melodies tell the difference between strength and weakness. Through the Yin and Yang we can see how well the enemy's weapons and equipment are. Fighting meritoriously, orders came that opening the Mufu to hold the right of military commanding. Troops stationed in the city of Changwu and the night beacon fire can shine the city of Chenggao not far away." [1]

The sixth year of Tianhe (571), Emperor Wu had been in power for ten years and the Northern Zhou grew stronger and stronger. Yu Xin wrote An Ode to Hualin Garden Horse Shoots on March Three, in which he praised the prosperity of the Northern Zhou Dynasty. The ode reads: "When I started my business in the great Zhou, Nanzheng (an official position) was in charge of the affairs of the sky, and Beizheng (an official position) was in charge of the affairs of the people and the land. I put down the rebellion of the nine Li nations and wiped out the rebellion of the three Miao nations. Each government office is assigned its own function. The emperor will have the basis for the rule of the country and thus the country can be in a long-term peace and stability, not only from the merit of heaven and earth, but also from the sun and the moon together." Yu Xin called the Northern Zhou regime "My Great Zhou" in his ode, which was obviously an expression of recognition of the Northern Zhou regime. In the ode, Emperor $\mathrm{Wu}$ was also praised for his “The Emperor Wu of the Northern Zhou Dynasty followed literature for his martial arts with his excellent morality and ability. Boyi was in charge of the temple of worship officials, which has a clear record in the Three Rituals. Kui was appointed as the music officials during the period of Yao and Shun and made the famous Nine Songs. You (referring to the Emperor $\mathrm{Wu}$ of the Northern Zhou Dynasty) restrained yourself as well as paid attention to the ceremonial appearance, creating neat military appearance and looked majestic-looking. You live simply and in all your thoughts are the concerns about people and the world. If it doesn't rain for a long time, you'll be very sad. When the harvest fails, you are even more devoted to your people." The emperor's strategy of governing the country made "Emperor Wu of the Northern Zhou had a virtuous government and ruled the country in full peace" more than "respecting the venerable senior men." It can be seen that the political stability of the Northern Zhou under the reign of Emperor at that time makes it a country of morality.

Yu was a household name for his odes, and his praise of the Northern Zhou Dynasty played a good role in public opinion in the situation of The Three Kingdoms made up of the Northern Qi Dynasty, the Northern Zhou Dynasty and the Chen Kingdom.

\section{Writing the Temple Poems for the Northern Zhou Dynasty}

Since the Eastern Jin Dynasty, there is a confrontation between the north and 
the south, in which the northern minorities and Southern Dynasties in Eastern Jin have been fighting over who is the orthodox Chinese culture. Southern Dynasties in Eastern Jin had a superior position in the "ritual and music charter", namely the cultural relic system and academic culture, which was the main reason for its superior position in the orthodoxy. Not wanting to be left behind, the minority nationalities in the north forged Chinese articles on rites and music to carry out the orthodox reconstruction movement. The reform of Emperor Xiaowen of the Northern Wei Dynasty was the peak of learning Han culture, whose comprehensive and profoundity is unmatched, overshadowed the Southern Dynasties. The Northern Wei Dynasty later was divided into two parts, "The first emperor of the Northern Zhou Dynasty welcomed the Emperor Wu of the Northern Wei Dynasty into Hangu Pass without playing etiquette or music." But in the Southern Liang Dynasty, Xiao Yan, "who specializes in dress, make-ups and music etiquette research, making intellectuals in the central plains feel that the Liang Dynasty is the most orthodox place of culture" [2]. "In the first year of Emperor Gong of the Wei Dynasty, Jing state was pacified, and a large number of Musical Instruments of the Liang Dynasty were obtained and distributed to the relevant departments... Although the Ming emperor of the Wei dynasty corrected the problems of music in the Wei Dynasty, they still did not reach the best level. In the first year in Tianhe of Emperor Wu of the Wei Dynasty, Emperor Wu created the Dance of Cloud and Mountain for the first time to prepare for the six court dances. Sacrifices for heaven, earth and ancestors, etc. all need to use the court dances... Later, it was determined as the standard of etiquette and music, as the music dance for the emperor to sacrifice ancestors. And he also created musical scores that were in tune with the dance." [1] Before Yu Xin entered the north, he was an important official in the Southern Dynasty and a literary champion, familiar with the rites and music of the Liang Dynasty. Under the appointment of emperor $\mathrm{Wu}, \mathrm{Yu}$ Xin composed temple songs and poems. Winter in October in the third year of Jiande, the six songs were accomplished and $\mathrm{Yu}$ Xin also made Congratulating Memorial on the New Songs to express congratulations. Yu Xin was in favor of Emperor Wu's move and tried to do it. The sixth volume of $Y u$ Zishan Collection involved the temple songs of Yu Xin, including Ode to Yuanqiu in the Northern Zhou Dynasty, Ode to Fangqiu in the Northern Zhou Dynasty, Ode to Five Emperors in the Northern Zhou Dynasty, Ode to the temples in the Northern Zhou Dynasty, Ode to Daxia in the Northern Zhou Dynasty, and Ode to Yanshe. It can be said that Yu Xin of the Northern Zhou Dynasty made a remarkable achievement in the process of the orthodoxy of Chinese culture.

\section{Writing Inscriptions and Epitaph for the Meritorious Statesman of the Northern Zhou Dynasty}

Yu Xin not only composed temple songs for the Northern Zhou Dynasty to make the rites and music elegant and pure, but also wrote inscriptions and epitaph for the meritorious statesmen of the Northern Zhou Dynasty. The for- 
ty-one volume of Zhou Shu, Yu Xin Bibliography carries "Emperor Ming and Emperor $\mathrm{Wu}$ were always fond of literature, and Yu Xin was especially favored. When the princes Zhao, Teng make friends with Yu Xin sincerely, they were like friends in days of simple life. Most of the royal stele records were written by $\mathrm{Yu}$ Xin under the request of the nobles. Only Wang bao is the equal of Yu Xin, and no other scholar can match him." [3] Four volumes in the $Y u$ Zishan Collection record the inscriptions and epitaph written by $\mathrm{Yu}$ Xin for about forty meritorious statesmen of the Northern Zhou Dynasty, most of whom were national generals of the Northern Zhou Dynasty, either being Xianbei people or Han people who were given Xianbei names. For example, he had written epitaphs for Zheng Wei, general of the Northern Zhou Dynasty, riding general Yuwen Xianhe, hussar general Chen Daosheng, General Sima Yi and Wu Mingche. Yu Xin was willing to write inscriptions and epitaph for them, which made it easier for him to integrate into the ruling group of the Northern Zhou Dynasty.

\section{Concerns about the Extinction of the Northern Qi Dynasty by Northern Zhou Dynasty}

The regime of the Northern Zhou formed a situation of tripartite confrontation with the Northern Qi in the east and Chen Dynasty in the south. Since Emperor $\mathrm{Wu}$ of the Zhou Dynasty committed the completion of unification, thus, wars between the Northern Zhou, the Northern Qi and Chen were inevitable. Bibliography of Emperor Wu of the Northern Zhou Dynasty recorded that there were five wars between the Northern Zhou and the Northern Qi: 1) The third year in Baoding, national general Yang Zhong rating ten thousand rides and the Turkistan expedition attacked Qi. Spring in the first month of the fourth year in Baoding, Yang Zhong broke the Great Wall of the Northern Qi and returned until fighting to Jinyang. 2) Winter in October of the forth year in Baoding, the Norther Zhou instructing senior general, Dazhongzai (an official position), Duke $\mathrm{Hu}$ of Jin to lead an army to attack Qi. In November, Yuchi Jiong commanding team surrounded Luoyang, the duke of Qi Dynasty, Yuwen Xian garrison troops in Mangshan mountain, and the duke of Jin Yuwen Hu garrison troops in Shan state. The army was defeated in December and then returned. 3) In September of the fourth year in Tianhe, the state general and the Duke Xian of Qi were dispatched to build Chongde and other cities in Yiyang. 4) Spring in the first month of the sixth year in Tianhe, the state general and the Duke Xian of Qi were dispatched to lead the army to defend against the general of the Northern Qi, Yielv Mingyue. 5) In the sixth year of Jiande, the Northern Zhou sent troops to destroy Qi. Judging from the results of these five wars, the Northern Zhou lost only once. Obviously, the Northern Zhou had a clear advantage in the confrontation between the two armies.

$\mathrm{Yu}$ Xin revealed the concerns on the war of the two sides in his poems. In the fourth year of Baoding, when Yuwen $\mathrm{Hu}$ attacked the Northern Qi, Yu Xin served as the governor of Hongnong county and wrote the Sutras Inscription of 
Wuzhang Temple in Hongnong County of Shan State. He expressed great concern about the war and said "The emperor ordered me to guard this area... No sooner had I arrived than the enemy invaded." and said in Feeling Expressing "It is heard that the enemy's military siege of our army will not be end this year." But in the end, the Northern Zhou army was defeated and returned. Yu Xin can only make an exclamation that "the Northern Zhou failed completely and returned north without any success". The forth year in Tianhe, defender of Kong city was killed and the Northern Zhou emperor sent Yuwen Xian to build the wall for defense on the one hand, and on the other hand wrote a letter to Northern Qi, hoping for a peaceful solution. Yu Xin wrote letters to the deacon of Heyang in Qi in April and October in the forth year of Tianhe respectively and the April letter was written in the name of Emperor Xian of Qi. The November letter was written in the name of Liang Xin, the general manager of Shaanxi province. Both of the two letters were written in the hope of "improving the situation" [1] and both was a preparation for the Northern Zhou dynasty to destroy the Northern Qi. Finally, in the sixth year of Jiande, the Northern Zhou Dynasty pacify Ye capital and the Northern Qi was destroyed. At that time, Yu Xin served as the provincial governor of Luo state. Although $\mathrm{Yu}$ was not in Chang'an, he wrote poems to express his inner joy. It said in the Poem Sent to Luo State for News of Victory, “King Wu's conquest over Yin, and the vassals led their armies to meet in Mengjin and King Wu defeated King Zhou that day. The drum on Lei door can be heard a hundred miles away and the sword's (which belonged to Emperor Gaozu of Han Dynasty for using to cut the white snake of) light is even more dazzling than the gods." [1] In Poem for Celebrating the Pacified Ye City, he praised that “Ancient 'King of Zhou' and 'Xuanyuan' and other wise men in the war were not as resourceful as the Northern Zhou Dynasty's Emperor Wu, Yuwen Yong, who was tactical and able to win the war by easily overcoming the opponent and peace the world. The reign of Emperor $\mathrm{Wu}$ of the Northern Zhou Dynasty was already very extensive and only the territory of Wuyue and the overseas Lin state did not belong to the Northern Zhou. The world was stable and the people were rich and the country was strong under their rule. Although they had such achievements, they still could not compare with the Northern Zhou Dynasty's Emperor Wu, Yuwen Yong. The whole world praised Emperor Wu of the Northern Zhou Dynasty, yet could not describe his merits fully. The merit of Emperor Wu of the Northern Zhou Dynasty could not be expressed by the performance of all the six music, which eulogized the ancient sages." [1] It is clear that Yu Xin hoped not only to unify the north, but also to unify the whole country. In the second year of Tianhe, the minister of Chenxiang state, Hua Jiao, led a group of people to seek refuge and support. The Northern Zhou Dynasty dispatched the governor of Xiang state, Yu Wen Zhi, the duke of Wei, to lead the army to assist, hence crusading to the south. Yu Xin, who was in office in the General Governing Office, wrote the poem Seeing off Prince Wei to the South, "The Northern Zhou army and the Southern Chen ar- 
my were facing each other across the river, preparing for war. The Northern Zhou army was encamped and had not yet defeated the Chen army. If you want to cut down Chen, you should first cross the river south from Guangling." [1] $\mathrm{Yu}$ Xin refers to the Chen Dynasty as a bandit in his poem. A sentence "The camp was moved because the enemy didn't surrender" is enough to indicate that he hopes that the southern expedition of Yuwen Zhi can wipe out the Chen Dynasty and unify the north and south.

During the war between Zhou and Qi, Yu Xin was very concerned about the war. In the period when the two sides sent envoys to each other, $\mathrm{Yu}$ Xin received envoys from the Northern Qi as envoys or returned to the Northern Qi as envoys. Summer in April of the fourth year in Tianhe, Qi sent an emissary to visit and $\mathrm{Yu}$ Xin received the emissary, drinking with him and wrote a poem named A Banquet with the Envoys of the State of Qi. In the autumn of the same year, Yu Xin was sent by the Northern Zhou Dynasty to pay a return visit to the Northern Qi dynasty. Yu Xin wrote a poem named, Inviting Qi Qiu to Drink in a $P u b$, saying "You had a very good reception and it was a pleasure to have a good drink with you." [1] Yu Xin, at this time, obviously represented the regime of the Northern Zhou Dynasty and was very adaptable to it.

\section{Worries about the Political Situation in the Late Northern Zhou Dynasty}

In June of the first year of Xuanzheng, Emperor $\mathrm{Wu}$, Yuwen Yong, passed away and Emperor Xuan, Yuwen Yun, ascended the throne. Emperor Xuan and Emperor $\mathrm{Wu}$ were very different, the latter of whom was fatuous and corrupt in politics and extravagant in life. "From the very beginning of his succession to the throne, he showed his desire, selecting the world's women to enrich the harem. He likes to boast about himself, refuses advice and disguises his mistakes. The curtains of the palace were decorated with gold and jade jewelry, dazzling and extremely luxury. Every time the courtiers were summoned for discussion, there was no mention of management on politics. He ostracized his ministers and had many jealousies." [3] At the beginning of his accession to the throne, Emperor Xuan killed column kingdom, Yuwen Xian, the King of Qi, for the crime of treason. The king Xian of Qi, was closely associated with Yu Xin, which was reflected in his numerous poems and essays. It was a man who had a close relationship with Yu Xin who was killed and had to remind him of his experience in the Liang Dynasty. In the chaos of Hou Jing rebellion, the princes of Liang Dynasty did not worry about foreign troubles, but killed each other. Yu Xin, who experienced the collapse of the Liang Dynasty, had a deeper understanding of the current political situation of the Northern Zhou Dynasty. At this time, it was impossible for him to escape completely. Instead, he stood in the position of the Northern Zhou Dynasty and tried his best to avoid the same fate as the Liang Dynasty. The work of his later years, Lament for the South not only expressed his thoughts about the rural customs, but also concealed the implication of ex- 
horting the rulers of the Northern Zhou Dynasty. In his ode, he expressed the feeling of "Driven by a dangerous situation, he worries about his later life" [1]. As a person who moved from the south to the north, Yu Xin put his life on the line for the sake of the political situation of the Northern Zhou Dynasty, which is enough to prove that he had fully adapted to the culture of the Northern Zhou Dynasty and integrated into the regime of the Northern Zhou.

\section{Conclusion}

To sum up, after the first year of Baoding in Emperor Wu, Yu's uncooperative attitude towards the regime of the Northern Zhou gradually changed into his identification with the culture of the Northern Zhou. Through actively engaging in politics, writing the temple poems for the Northern Zhou Dynasty, eulogizing the regime of the Northern Zhou Dynasty with poems, writing inscriptions and epitaph for the meritorious statesman of the Northern Zhou Dynasty, being concerned about the Northern Zhou Dynasty destroying the Northern Qi Dynasty, and being worried about the political situation in the late Northern Zhou Dynasty, he finally actively integrated into the Northern Zhou Dynasty.

\section{Fund}

Project funded: General Project in Scientific Research Program of Sichuan Education Department (Humanities and Social Sciences) in 2018 (project number: 18SB0614).

\section{Conflicts of Interest}

The author declares no conflicts of interest regarding the publication of this paper.

\section{References}

[1] Yu, X. (2000) Notes of Yu Zishan Collection. Ni, F., Trans. Zhonghua Book Company, Beijing.

[2] Li, B.Y. (1972) Northern Qi Shu. Zhonghua Book Company, Beijing.

[3] Linghu, D.F. (1971) Zhou Shu. Zhonghua Book Company, Beijing. 